\title{
UNA ESCRITORA LATINOAMERICANISTA. ENTREVISTA A ANA PIZARRO ROMERO*
}

\author{
IGNACIO VIDAURRÁZAGA MANRÍQUEZ**
}

\section{"LOS INTELECTUALES TENEMOS QUE TRATAR DE GENERAR SEN- TIDOS PARA EXPLICARNOS ESTO QUE APARECE ENMARAÑADO”}

En medio de la pandemia, de la destrucción del planeta por el afán de lucro, de enfrentamientos nacionales e internacionales ciegos por el poder político. En medio de desgarradoras migraciones y abismos en la sociedad, y de "las tinieblas", que decía Hanna Arendt, los intelectuales tenemos una necesidad urgente: la de pensar el presente ya que el pasado no lo está iluminando. Generar escenarios de futuro en donde la tecnología, el atisbo del universo y sus destellos vayan de la mano con la conciencia de que no es que la naturaleza pertenezca al hombre, que la destruye y la domina, sino que formamos parte de ella y es urgente establecer con ella un diálogo. (Ana Pizarro, Palabras de agradecimiento en el acto de recepción de la Medalla Haydée Santamaría).

$\mathrm{L}$

Os LAzos de Ana Pizarro y Concepción vienen desde lejos y evidencian trabajo y vocación por el estudio y una constante búsqueda. En 1963, al egresar de Pedagogía en Castellano, obtenía dos premios: a la Mejor Práctica Pedagógica y, quizás el más significativo, el Premio Universidad de Concepción. otorgado al o la mejor estudiante de su promoción. Son infinitas memorias y sentimientos los que la enlazan con la Región del Biobío.

Su trayectoria se extiende por más de 50 años de actividad intelectual, investigación académica y de publicaciones individuales y asociadas. $\mathrm{Pa}$ ralelo a un quehacer docente en diversas universidades de a lo menos dos continentes. La de ella es una historia intelectual con muy diversos tópicos de búsqueda: lo latinoamericano y lo amazónico; la historia de la cultura; la

* Entrevista sostenida en Santiago, el 21 de septiembre de 2020.

** Periodista y Magíster en Literatura Hispanoamericana y Chilena, Universidad de Chile, Santiago, Chile. Correo electrónico: ividaurrazaga@yahoo.com. Orcid: https://orcid.org/0000-0003-2099-835X. 
literatura de mujeres y de los pueblos originarios; Gabriela Mistral y Vicente Huidobro, además de otros diversos vértices que son o han sido líneas de interés, curiosidad e investigación.

Con Ana Pizarro siempre hay variados tópicos de conversación, pero para poder "amasarlos" será siempre necesario buscar enfocarse. Hemos conversado de los 50 años de Salvador Allende y de la Unidad Popular, la pandemia, y la Amazonía y el mal gobierno de Bolsonaro. Además de su cercano y familiar conocimiento de Miguel Enríquez, padre de su sobrina Javiera. A la hora del recuerdo lo retrata joven e intenso como lo conoció:

A Miguel lo veo lejos de lo sacrificial, lo asocio a facetas menos públicas, pero absolutamente propias: como su contagiosa risa y su humor negro.

El foco de diálogo acordado para este encuentro busca responder a lo menos tres temáticas que caracterizan su fecunda y extendida trayectoria: ¿Cómo se hizo latinoamericanista y cuál fue la génesis de uno de sus mayores proyectos: la trilogía de volúmenes de América Latina: Palavra, literatura e cultura, Sao Paulo, publicado en 1993?, ¿cuáles son los antecedentes de la literatura de mujeres desde su contacto y estudio de esas precursoras? Y, por último, sobre el rol de los intelectuales en esta hora presente.

Doctora en Letras de la Universidad de París, luego maestra de conferencias de La Sorbona y hasta hace algunos años profesora e investigadora en literatura y cultura de América Latina del Instituto de Estudios Avanzados de la Universidad de Santiago de Chile, sus publicaciones individuales conforman un extendido listado: su novela La luna, el viento, el año, el día (1994a); De ostras y caníbales (1994b), Premio Municipal de Literatura de Santiago, categoría Ensayo; El sur y los trópicos. Ensayos de cultura latinoamericana (2004); Gabriela Mistral: El proyecto de Lucila (2005). El 2002 fue becaria de la John Simón Guggenheim y el 2011 reconocida por Casa de las Américas con el Premio Honorífico de Ensayo Ezequiel Martínez Estrada. Hace 19 años que conoce y estudia la Amazonía, y es considerada una de las mayores expertas en el ámbito de la cultura, de lo que es expresión su texto Amazonía: el río tiene voces. Imaginario y modernización (2009).

En esta extendida cuarentena trabaja en una antigua casa con corredor y un jardín que ilumina una hilera de habitaciones. Allí, vive junto con su sobrina-hija Javiera Enríquez y una inquieta perra que se llama Naia. Y muchos libros. Quizás son unos 5000 o incluso más. Ahí están sus temas, sus amistades; los intercambios y las asistencias a congresos y cursos. Demasiadas huellas de todas o muchas de sus itinerancias. 


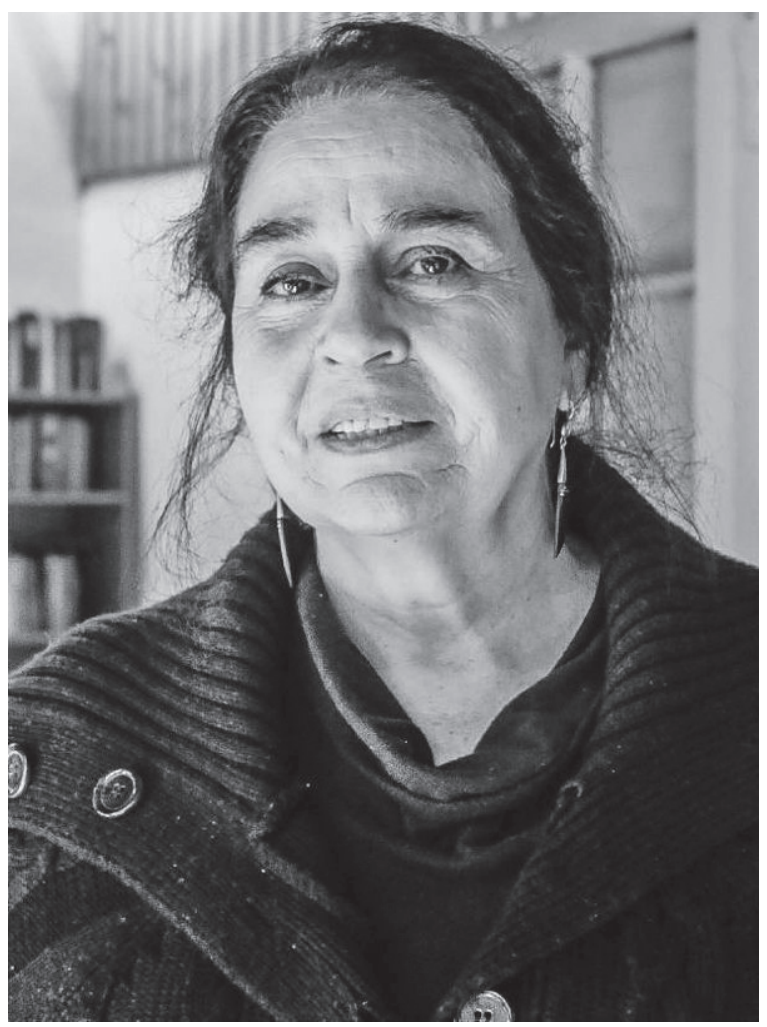

A. Pizarro. Santiago, Instituto de Estudios Avanzados USACH, 2016.

Mis libros son mis ventanas al mundo, creo que me siento insegura sin ellos. Para el golpe, los militares quemaron mi biblioteca, se la llevaron, y después la segunda que tuve en Francia, la debí dejar porque no tenía plata para trasladarla a Venezuela. Aquí, están los textos reunidos a partir del 80 o el 82. Quiero mucho mis libros, les tengo un especial cariño, incluso me gustaría estudiar restauración para reparar algunos. En realidad me gustaría estudiar tantas cosas, inclusive cultura árabe, pero para eso creo que necesitaría otra vida.

En el plano intelectual hay un grado inexistente en la formalidad de la academia, que no está asociado ni a diploma, ni a ceremonia alguna. Se otorga de boca en boca particularmente por quienes han trabajado de cerca con la persona aludida: sus estudiantes y colegas. Muchas veces la persona 
nombrada como maestra puede no enterarse de esa distinción o denominación. Desde hace muchos años, Ana Pizarro Romero tiene con creces esa condición, quizá ya está enterada, pero desde su sobriedad ni lo alardea ni lo presume. Sencillamente la ejerce.

\section{LA IDENTIDAD EN LA DIVERSIDAD}

Precisamos volver a los orígenes de la historia entre tú y los estudios culturales $y$ literarios de América. ¿Cómo aconteció esa trayectoria que fue desde Chile a Francia y tu retorno e itinerancia por Latinoamérica?

-En literatura comencé a trabajar en Chile en la Universidad de Concepción. El año 63 me fui por primera vez a Francia y comencé un doctorado. Sentía que no me bastaban los estudios literarios, que además necesitaba explicarme el mundo. La literatura me daba una explicación, pero yo necesitaba ir más allá. Es ahí que comencé a asistir a los cursos de Lucien Goldman y desde ahí lo mío fue trabajar la literatura en la sociedad.

Mi tesis de doctorado era muy literaria, pero creo que algo tenía de inserción social. Era sobre Vicente Huidobro, pero ya empezaba a ver el espacio entre dos culturas, era a la vez un proyecto literario, cultural y social. Luego, ya estábamos en la Unidad Popular y comencé a contactarme con el campo mapuche. Ahí me di cuenta de la importancia de la oralidad. Eso me entusiasmo mucho porque percibí que la manera de hablar castellano de los mapuche era y es pura poesía. Lo relacioné con lo que ya conocía de la épica medieval, y ahí se me abrió el campo hacia la oralidad.

Posteriormente, cuando salí exiliada de Chile a Francia en diciembre del 73, me otorgaron una beca del CNRS (Centro Nacional de Investigación Científica) y ahí comencé a elaborar como proyecto el estudio de la literatura latinoamericana. Era sustancial trabajar la literatura en la cultura y en la sociedad. Todo coincidía, porque esa vuelta de la mirada desde los sujetos de la colonización estaba sucediendo simultáneamente en otros continentes. Por ejemplo, en África, estaban empezando a conocerse unos primeros estudios. Recuerdo una conversación con Samir Amin sobre mi trabajo en que me habló de un escrito sobre las cruzadas pero vistas ¡desde los árabes! Claro, era Amin Maaluf. 
$\mathrm{Al}$ irme de Chile era consciente de que esta manera de pensar la historia no se había hecho en nuestro continente y ese sería el gran problema que luego tendría en las reuniones de la Asociación Internacional de Comparatistas en Europa, donde tenía de interlocutores a unos señores 70 años para arriba. Era la única mujer, joven además y tenía que discutir con ellos, e interesarles en una literatura que desconocían. Ahí también me di cuenta, nuevamente, de que ser mujer implicaba una relación social muy difícil, entre otras connotaciones. Para ellos era muy chocante que yo relacionara la cultura con la sociedad. El problema en el fondo era esencialmente político, veían a la literatura latinoamericana con un criterio colonial, porque aunque la literatura comparada a comienzos del siglo XX se desarrollaba como una voz antifascista y antinacionalista, por así decirlo, después tendría una dimensión muy eurocéntrica. Hoy, le hemos dado un cariz diferente.

Comencé por mostrar que el nacionalismo tenía muy diversas caras. Para nosotros la reivindicación era latinoamericana, los países colonizados necesitaban reivindicar primero un proceso identitario y después pasar a otras instancias, entonces no podía ser lo mismo el nacionalismo en Europa que en los países colonizados. En esa época el pensamiento de René Etiemble, antieurocentrista, con quien compartía oficina en La Sorbona, me iluminó bastante, así como el de Ángel Rama y de Roberto Fernández Retamar. Ellos me ampliaron el mundo. Recuerdo una expresión de Rama en Marcha, cuando visitó Israel, país en formación entonces y escribió: Construir un país es lo de menos, lo difícil es construir una cultura. Después, el proyecto fue integrado como tal para ser publicado en inglés. Pero, a esas alturas, sentí que no valía la pena seguir ahí y lo hablé con Antonio Cándido, me encontró razón y nos salimos del programa para independizarlo. En paralelo, yo me había trasladado a vivir a Venezuela.

\section{UNA OBRA MAYOR: AMÉRICA LATINA: PALABRA, LITERATURA Y CULTURA}

En tu historia intelectual, destaca una obra señera, producto de este proyecto, de la que fuiste organizadora y editora y que ciertamente fue un cimiento de todas las demás, me refiero a los tres volúmenes de América Latina: palabra, literatura y cultura publicadas en Sao Paulo, Brasil, por la editora Unicamp. Después, el 2013 la Universidad Alberto Hurtado publicaría en Chile el volu- 
men III Vanguardia y modernidad, de 956 páginas. Es una mega obra y salvo en muy contadas bibliotecas todavía no es posible encontrar la obra completa. ¿Su edición íntegra en Chile es un propósito aún pendiente? ¿Crees que esos tres volúmenes tienen aún vigencia?

-Absolutamente. Antonio Cornejo Polar, gran crítico de nuestro continente, decía: cómo hacer una historia que contenga los elementos de su propio devenir, que genere su propia crítica, ese es un poco el sentido. Una actitud siempre de apertura, de pensar que algo sucede en un momento, que puede ser visto de múltiples maneras, pero que la mirada siempre debe proseguir y evolucionar.

Pero, volvamos a los orígenes y contextos, que es lo que tú me preguntabas.

Finalmente, nuestra investigación se publicó en 1993 en Brasil, en español y portugués, en el Memorial de América Latina; fue la culminación de 15 años de trabajo y de vida en distintos países. Cuando la terminé ya estaba de vuelta en Chile. Acá siempre hubo poco interés, en Brasil está en todas las bibliotecas universitarias y circula en otras partes del mundo.

Cuando empecé ese proyecto el trabajo era enorme, diría desproporcionado y no había financiamiento, solo había que apelar a las voluntades. Teníamos que ir pensando el proyecto y al mismo tiempo comenzar a convocar participantes dentro de lo mejor que tuviera la crítica latinoamericana. Pero yo venía de un mundo y un medio donde íbamos a cambiar la vida, entonces si habíamos pensado que todo era posible, entonces... ¿ ¿cómo nos iba a amilanar un proyecto académico?

¿Recuerdas cuáles fueron las preguntas iniciales de esa ambiciosa investigación y luego obra?

-Sí. ¿Qué es América Latina?, ¿cuáles habían sido sus denominaciones?, ¿cuáles sus fronteras? Era preciso contextualizar que había un proceso internacional de luchas por las identidades nacionales de los pueblos coloniales. No había una historia literaria en un sentido amplio. Tampoco una historia de la cultura y eso me impulsó a que era necesario hacer una historia literaria. Después, todo se fue ampliando y fue necesario incluso cambiar el título. Recuerdo que le pregunté a Cándido, que era la persona sabia que yo escuchaba, le dije: qué le parecía si en vez de historia literaria le llamábamos América Latina, palabra, literatura y cultura. Porque las palabras siempre importan; como se nombren los proyectos y los libros con mayor razón. 
Entonces hablé de "palabra", por la oralidad. Y cultura, porque sucede que en nuestro mundo literatura y cultura son casi una misma cosa: la oralidad, la escritura ideográfica, las pictografías, el canto, el texto escrito tienen sólidas relaciones.

Por ejemplo, las representaciones indígenas de la muerte de Atahualpa son procesiones, son cantos, literatura y teatro, porque todo está mezclado. $\mathrm{Y}$ así comenzaron los giros. Lo primero fue incorporar a Brasil, porque de otra manera era absurdo hablar de América Latina. También, enseguida integramos al Caribe, cuyo estatus no era muy claro, pero cuyas articulaciones históricas con el continente se expresan en elementos históricos y culturales comunes. Un solo indicio importante: la Carta de Jamaica de Simón Bolivar, uno de los textos fundacionales de nuestra historia política está escrita en el caribe anglófono.

¿De inmediato tensionaban el castellano en su condición de lengua única y característica de América?

-Efectivamente, pusimos en la discusión el tema de la lengua como unidad del continente, elemento que hasta ahí había establecido el corpus y el canon en la historia literaria. Pero, evidentemente, la idea del español como el centro articulador, había dejado de lado no solo a Brasil, sino a una multitud de nuestras culturas indígenas. Es decir, al aceptarlo estábamos situando nuestra definición con los mismos criterios coloniales. Lo que nos une es la cultura en la historia. A la vez, teníamos que incorporar a la cultura a los latinos en los Estados Unidos, un fenómeno propio del continente desde mediados del siglo XX, que a partir de migraciones masivas estaba generando una cultura de perfil específico, relacionada con la de origen.

Todo lo que hicimos esos años, significaba también una ruptura no solo con la historia literaria tradicional, sino con las concepciones históricas sobre el continente que proveían y proveen delimitaciones estáticas regidas por lógicas políticas o militares sin apenas percibirlo.

Por cierto, nosotros también teníamos una lógica política, pero de un signo diferente, al situar como referente de la discusión la idea de la colonización. Así, nos alejábamos de la historia literaria tradicional cuyos referentes esenciales eran geográficos o lingüísticos. Este alejamiento no era un propósito, sino el resultado de una revisión epistemológica. Lo central, lo que creo que articulaba y articula la idea de América Latina es la cultura, una cultura traspasada por el signo de la colonialidad. No existe una sola literatura. Existe la literatura indígena que es oral, las literaturas populares 
que son orales y son otras formas literarias, como también existen otras escrituras y no solo la alfabética.

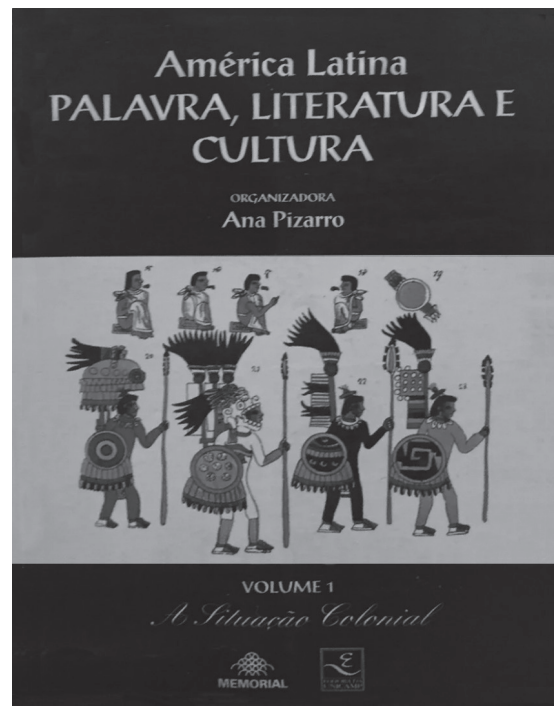

Edición brasileña de América Latina. Palavra, literatura y cultura, de Ana Pizarro. Vol. 1, 1993.

Contactar y reunir a cien intelectuales de primer nivel en esos años debe haber sido un asunto de porfía mayor, de motivación extraordinaria y además sin medios, jsin correo electrónico, ni wasap, ni celular!

- Todo lo hicimos por intermedio de cartas, cuesta imaginar lo que era eso. Recuerdo que cuando iba a una reunión viajaba con maletas llenas de documentos y de fotocopias. Había que esperar meses por una respuesta, que algunas veces nunca llegaba.

¿Grababas?

-Algunas veces grabamos para el primer libro. Creo que para el segundo también grabamos, pero en la tercera reunión fui tomando notas: allí discutimos la organización de los materiales sobre la base de lo propuesto por Rama y Cándido. 


\section{UNA INTELECTUAL INOLVIDABLE}

En ese proceso de investigación emergen algunas mujeres muy significativas $y$ entre ellas Marta Traba ¿Qué podrías reseñar sobre ella?

-Marta pertenece más a los años 60, es un personaje increíble. Nace en Buenos Aires y luego vive en Colombia, porque se casa con un colombiano, hijo de un escritor de apellido Zalamea. Después se separa, tiene dos hijos, se une a Ángel Rama y se van a vivir a Montevideo. Ella fue muy conocida en Colombia. Viaja por América Latina, EE.UU. y Barcelona. Paralelamente, publicó varias novelas, una de esas se llama Homérica Latina, como Homero; otra, Conversación al Sur, que es la historia de tres mujeres que tienen hijos detenidos desaparecidos.

Y además Marta fue una gran teórica. Esa es una característica muy interesante, porque a las mujeres que piensan en general no se las considera, y ella desarrolló teorías sobre la cultura y la plástica latinoamericana. Entre sus definiciones están las áreas abiertas y las áreas cerradas en la pintura: áreas abiertas son las que recogen y absorben los elementos del exterior, por ejemplo, las vanguardias. Mientras, denominó como áreas cerradas a las culturas que son muy profundas en América Latina, como la quechua, la aymará, y luego la pintura que surge de esas culturas las denominará como muy resistentes al cambio.

Pienso que Ángel Rama no es Ángel sin el pensamiento de Marta Traba, y al revés, porque ella incorpora a Rama a su pensamiento sobre la plástica. Ambos van coincidiendo desde sus respectivos saberes y experiencias en múltiples miradas.

Marta a veces fue muy incomprendida, porque tenía un carácter muy fuerte. Recuerdo que escribió un artículo que fue bastante polémico, eran los primeros artículos feministas, y ahí decía que la escritura de mujeres -y yo encuentro que tenía razón en esa época- era una escritura inicial, que se fundaba mucho en los sentimientos. La escritura de mujeres tenía algo propio y que era una manera de sentir la vida diferente de los hombres. Esto es cierto, en la medida en que las mujeres no tenían acceso a la escritura ni a la publicación y tampoco una práctica de escritura. Ciertamente, hoy la situación es muy distinta.

Para mí lo importante es si la escritura es buena o es mala. En ese tiempo la escritura femenina era muy incipiente. De esa época son los nombres de Rosario Ferré, de Puerto Rico, que era amiga de Marta, o Ana Lydia Vega, de allí también. Las mujeres en México también empezaron a manifestarse 
en la escritura. En Argentina hacia fines de los 60, 70, ya había una escritura de mujeres bastante sólida. En México la escritura de Margo Glantz es una maravilla, o la de Maryse Condé en el Caribe, o Ana María Gonçalves en Brasil. Todas son grandes mujeres que desde una perspectiva inicial de lo subjetivo interpretaron otro modo de ver la historia.

\section{PENSAR LATINOAMÉRICA}

¿Cómo hoy se está pensando América Latina? ¿Quién puede publicar para toda América?

-Todo es difícil, muy difícil. Por una parte, surge el internet y en principio estamos en apariencia todos más conectados, pero sucede que junto o previo está surgiendo el neoliberalismo con el pensamiento economicista por delante que ha invadido todo, eso disgregó el pensamiento intelectual humanista del continente.

También, entró en crisis una forma de pensar América Latina, esa de los años 60 que lo hacía monolíticamente. De pensar la unidad latinoamericana como si fuera una sola cosa, y sucede que no es así. América Latina es una diversidad que está articulada, que tiene una especie de estructura de base histórica y cultural en común, pero que ha generado sociedades con similitudes y diferencias. Una de las posibilidades de articularse para pesar como bloque en el contexto mundo es a partir de la cultura. Hoy, ya no podemos pensar exactamente como lo hicieron en el siglo XIX los libertadores, existen nuevos elementos para pensar el humanismo de las periferias y simultáneamente están surgiendo un pensamiento asiático y africano interesante.

Hubo un tiempo en Latinoamérica en que se les preguntaba a los escritores, como Carlos Fuentes o Gabriel García Márquez. Después se les ocurrió preguntar a los economistas, porque hoy nadie le pregunta al escritor sobre América Latina. Aparentemente, quienes tienen las respuestas o imaginan futuros son los economistas o los políticos, entonces considero que el pensamiento neoliberal hizo que los intelectuales humanistas pasaran a un segundo plano. En la actual situación todas las preguntas son válidas y es por ello que considero que los intelectuales de todas las disciplinas deben plantear sentidos y arriesgar respuestas.

En el anterior contexto, ¿cómo enlazarías desde la literatura a Gabriela Mistral, Alfonsina Storni, María Loynaz, Juana de Ibarbourou? Y desde la plásti- 
ca a Frida Kalho y Eleonora Carrigton desde México, y desde Brasil a Tarsila do Amaral o Anita Malfatti?

-Ellas son las mujeres que marcaron con su presencia el comienzo artístico del siglo XX. Todo eso estuvo sucediendo en las primeras décadas del siglo $\mathrm{y}$ a veces hasta la mitad. En algún momento escribí sobre el invisible college que ellas conformaron. Lo que hoy se llamaría construcción de redes que establecieron, y que se ha percibido poco. En realidad, entre las cuatro primeras hubo correspondencia, amistad y encuentros. En Cuba fueron connotados los de Loynaz con Mistral, porque, además, se pelearon ostentosa pero elegantemente.

Recuerdo que entrevisté a Dulce María Loynaz en febrero de 1993, cuando fui jurado del Premio Casa de las Américas. Era una aristócrata de las antiguas de Cuba, su apariencia era un tanto desgreñada, mientras conversábamos, a momentos trataba de ordenar su cabello. Vivía en una casona preciosa en el barrio El Vedado de La Habana. Una de esas casas antiguas, con zaguán, muebles antiquísimos, cristales, y jarros de porcelana guardados en vitrinas en medio de polvorientos y enormes salones. Ella caminaba poco, y tenía una cuidadora, seguramente puesta por el gobierno. Me intrigó mucho la grandeza de la decadencia en ese ambiente. Era un concierto barroco. Conversamos bastante, por mi parte, temía que se cansara. Me habló de la historia de Cuba, en la que su familia siempre jugó un papel importante. Su padre había sido un general que había estado exiliado en República Dominicana.

En mis recuerdos atesoro un diálogo hermoso con Dulce María. Le pregunté qué recordaba su padre de su exilio. Me dijo algo hermosísimo: el ruido del mar sobre las piedras. Me interesó mucho su relato histórico, y me sorprendió que en este, la Revolución no era más que un detalle en la historia de Cuba. Esa grandeza cubana me la trasmitió también Alejo Carpentier, cuando lo conocí en París en casa de Jorge Enrique Adoum, un gran amigo. No es común percibirla. Quizás hoy la esté expresando Leonardo Padura.

Por otra parte, Frida, Leonora Carrington, Remedios Varo conformaban un grupo bastante relacionado, según entiendo. No las he trabajado específicamente, pero ellas están en la estética vanguardista, más ligada al trabajo de las vanguardias de Europa y a la vez con un sentido mexicanísimo. Similar es el caso de Anita Malfatti en Brasil con Tarsila do Amaral. Mujeres tremendas que contribuyeron a dar vuelta la mirada sobre la pintura y sobre Brasil, con su espíritu vanguardista. 


\section{RECONOCIMIENTO DESDE CUBA}

En estos meses de encierro, recibiste la Medalla Haydée Santamaría del Consejo de Estado de la República de Cuba, en reconocimiento a tu contribución latinoamericanista. Fuiste reconocida junto a la compositora e intérprete Isabel Parra y el artista visual Hugo Rivera Scott. La valoración de vuestros aportes se origina en Casa de las Américas, ¿cómo la presentarías hoy?

-Como una institución fundadora del latinoamericanismo. Hay que recordar que se crea inmediatamente después del triunfo de la Revolución cubana, abriendo así un espacio de convivencia de los escritores, artistas visuales, y en general de la cultura latinoamericana. Antes de 1960, los escritores no tenían opción de reunirse dentro del continente. Fue en Cuba donde comenzaron las reuniones de escritores y gente de la cultura de diferentes países en un diálogo muy enriquecedor. Era el momento del llamado boom de nuestra narrativa que comenzó a generar obras que serían clásicas después, y que formaban parte de todo este movimiento alrededor de Casa. Muy pronto surgió la Revista Casa de las Américas, que se distribuyó a todo el mundo y el premio Casa para los nuevos escritores. Creo que Casa ha sido un ícono de la cultura no solo ilustrada, sino también popular y con una dirección latinoamericanista.

En aquella época, de escasa información, los y las jóvenes intelectuales chilenas esperábamos con ansiedad la Revista Casa, porque nos hablaba sobre un mundo más allá de la cordillera, que desconocíamos. Nuestras referencias eran sobre todo europeas o norteamericanas. Además, estaba la revista Marcha en el Uruguay, que conocíamos más de oídas, porque no llegaba a nuestro país. Todos esos fueron estímulos para comenzar a pararnos sobre nuestros propios pies.

La cuarentena de Ana Pizarro ha transcurrido entre lecturas, conferencias por zoom y revisión de textos para publicar nuevos libros. También, cocinando y conversando, mientras, añora retornar al campo familiar en Hualqui, para reunir nuevos frutos para preparar sabrosas mermeladas y así continuar oficiando de madre de sus hijos, de abuela y suegra múltiple.

En cuarentena por la peste, Santiago de Chile, septiembre 2020. 


\section{REFERENCIAS}

Pizarro, A. (1994a). La luna, el viento, el año, el día. México: Fondo de Cultura Económica.

Pizarro, A. (1994b). De ostras y caníbales. Santiago: Ediciones Universidad de Santiago.

Pizarro, A. (2004). El sur y los trópicos. Ensayos de cultura latinoamericana. Alicante: Universidad de Alicante.

Pizarro, A. (2005). Gabriela Mistral: El proyecto de Lucila. Santiago: Lom.

Pizarro, A. (2009). Amazonía: el río tiene voces. Imaginario y modernización.

Santiago: Fondo de Cultura Económica. 